\title{
1. Heat Transfer on D ZERO Run2b stave
}

\author{
Giobatta Lanfranco \\ Fermi National Accelerator Laboratory \\ Particle Physics Division / Silicon Engineering Group - Mechanical Dep. \\ e-mail: giobatta@fnal.gov
}

10 April 2002

\section{Abstract}

The temperature distribution on the silicon sensors and the cooling system performance for the D0 Run2b stave have been investigated. The tests have been carried out on a carbon fiber skin only stave, with and without heat input at two different chiller temperatures $\left(-9.1^{\circ} \mathrm{C}\right.$ and $\left.-19.1^{\circ} \mathrm{C}\right)$.

For a bulk temperature of $-14.5^{\circ} \mathrm{C}$ and a $14 \mathrm{~W}$ total heat load, the stave surface has reached a peak temperature of $+3.3^{\circ} \mathrm{C}$, localized under the readout chip. The "hot spot" in the hybrid region extends about twice the length of the hybrid with an average temperature of about $-4.6^{\circ} \mathrm{C}$ over this area. Beyond this the stave surface has a uniform temperature of $-11.5^{\circ} \mathrm{C}$. The film coefficient of the coolant has been calculated to be about $650 \mathrm{~W} / \mathrm{m}^{2} \mathrm{~K}$ using these measurements. A finite element analysis has confirmed the analytical calculations, providing a temperature profile consistent with what has been experimentally observed.

A further finite element study has been performed in order to predict the temperature distribution in the actual stave design (46mm wide; kapton core skin; $950 \mu \mathrm{m}$ thick hybrid; $7.2 \mathrm{~mm} \times 1.8 \mathrm{~mm}$ tube inner size; $-15^{\circ} \mathrm{C}$ bulk temperature; $700 \mathrm{~W} / \mathrm{m}^{2} \mathrm{~K}$ film coefficient). The silicon temperature ranges from about $-10.8^{\circ} \mathrm{C}$ far from the readout chips to about $0^{\circ} \mathrm{C}$ under them, the temperature drop between the sensor and the PEEK inner wall being $3^{\circ} \mathrm{C}$ and $10.5^{\circ} \mathrm{C}$ respectively.

\section{Test description}

In order to reduce the uncertainty affecting the thermal resistance between stave surface and inner wall of the cooling pipe, the $42 \mathrm{~mm}$ wide core is made only of Rohacell with on top a $250 \mu \mathrm{m}$ thick carbon 
skin $^{1}$. The cooling tube is $1.8 \mathrm{~mm}$ high by $5.2 \mathrm{~mm}$ wide (inner dimensions). Considering the high thermal conductivity of the silicon and the beryllia and the thin layer of glue ${ }^{2}$, the temperature values on the carbon fiber skin can be assumed close to what the silicon would experience.

The test setup is shown in Figure 1-1. The stave cooling line is mounted in parallel with a bypass line in order to regulate the head pressure on the stave. A second valve, placed between the stave outlet and the flowmeter, is used to fine tune the mass flow through the stave The coolant used is ethylene glycol $40.6 \%$ volume (refractivity index $n_{d}=1.376$ ). The steel ball flowmeter is manufactured by Gilmont, model GF 6540-1230.

At the inlet and outlet of the stave, two $1 \mathrm{~K} \Omega$ platinum RTDs (produced by Sensor Scientific) are placed in the coolant stream. Five sensors ${ }^{3}$ (two $10 \mathrm{k} \Omega$ thermistors Sensor Scientific WM103C and three Sensor Scientific 1K $\Omega$ RTDs) are mounted on top of the stave according to the scheme depicted in Figure 1-2; they are kept in place with Kapton tape while thermal grease helps to improve the thermal contact with the surface. The pressure drop and flow through the stave are also measured.

The heat load from the readout chips is simulated using two $120 \Omega$ strain gages (model Omega SG $30 / 120-\mathrm{LY} 40$ ) per hybrid; due to power supply limitations, each strain gage dissipates $1.75 \mathrm{~W}$ (the maximum operating heat load from 5 chips is expected to be $2.5 \mathrm{~W}$ ). The data acquisition system is based on a NI 4351 board produced by National Instruments. Figure 1-3 shows a typical data plot; the change in coolant temperature (from $-9.1{ }^{\circ} \mathrm{C}$ to $-19.1^{\circ} \mathrm{C}$, $\mathrm{T} @$ the chiller) can be clearly seen as well as the two segments with heaters on.

The room temperature was $24.3^{\circ} \mathrm{C}$.

\footnotetext{
${ }^{1}$ A previous set of tests has been performed on a stave with Rohacell core reinforced with a $250 \mu \mathrm{m}$ thick carbon fiber sheet, 2 mils insulating kapton, $600 \mu \mathrm{m}$ sensors and $400 \mu \mathrm{m}$ aluminum hybrids. Unfortunately the bad glue joint between the sensors an the hybrids has made it impossible to estimate the actual amount of heat transferred to the stave. Besides that, a leak in the cooling pipe has prevented any repairing of the stave.

${ }^{2}$ For a 3 mils glue joint over an area of $42 \mathrm{~mm} \times 50 \mathrm{~mm}, \Delta \mathrm{T}$ is about $0.35^{\circ} \mathrm{C} / \mathrm{W}$.

${ }^{3}$ The choice of different types of temperature sensors is made in order to compare the different performance of the devices. The thermistors are supposed to exhibit a faster response and, because of their relatively high impedance, smaller lead resistance error and self-heating error; however, for the present tests, the RTDs have shown higher accuracy and virtually no temperature offset between them.
} 


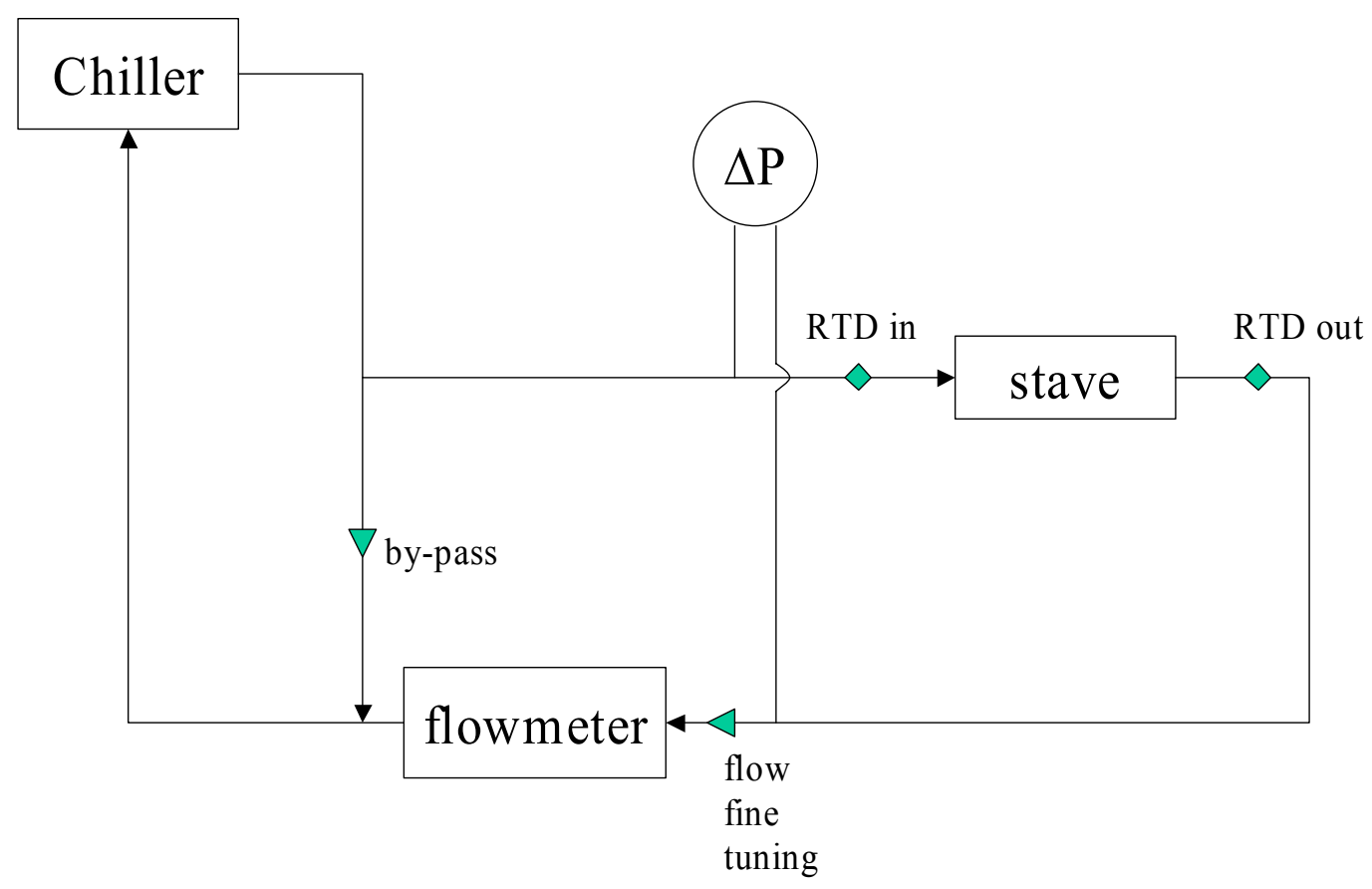

Figure 1-1 - Stave test setup

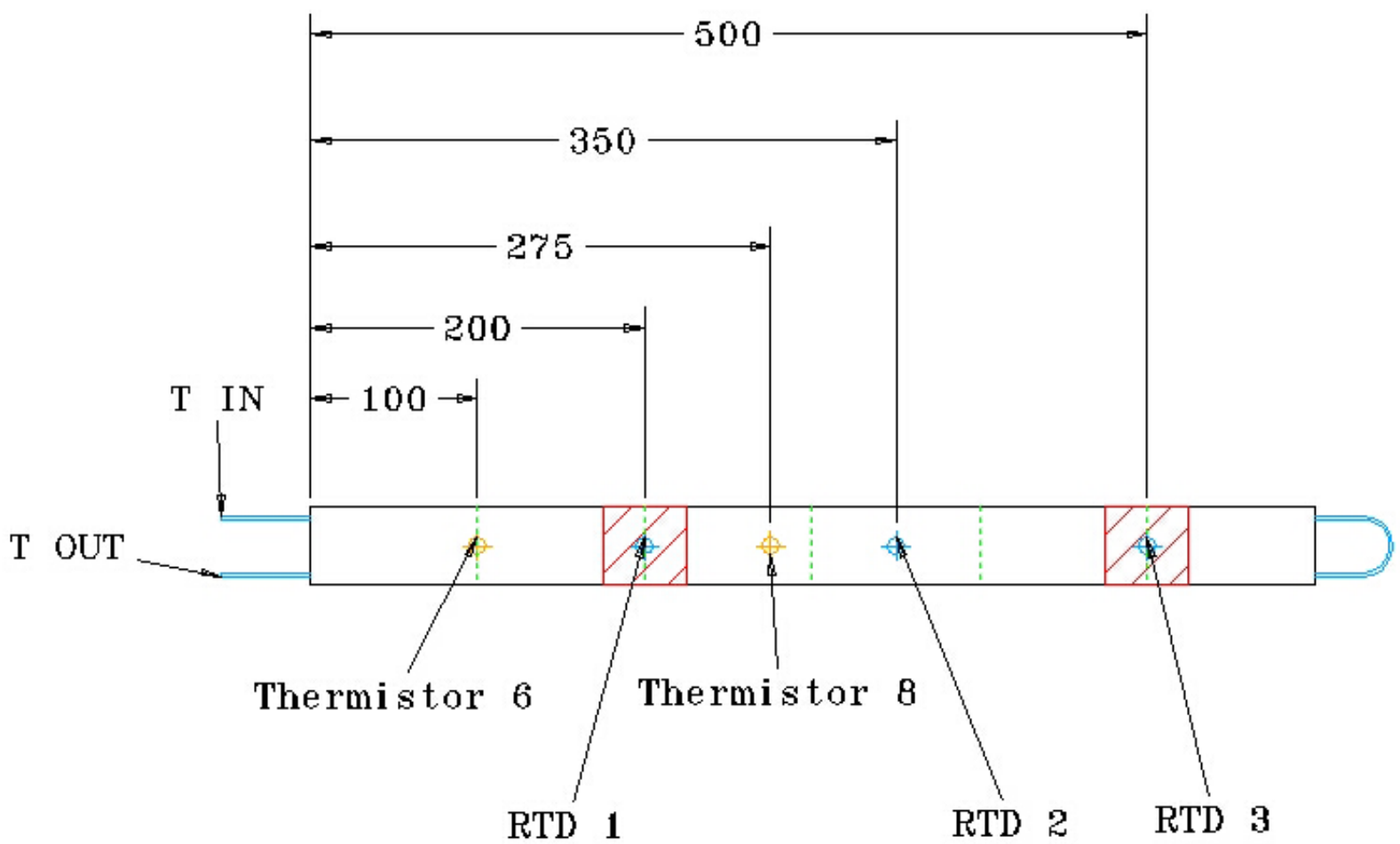

Figure 1-2 - Location of the temperature sensors in millimeters. In hatched red the areas where the hybrids are located; the edges of the silicon sensors are represented with green dotted lines. 


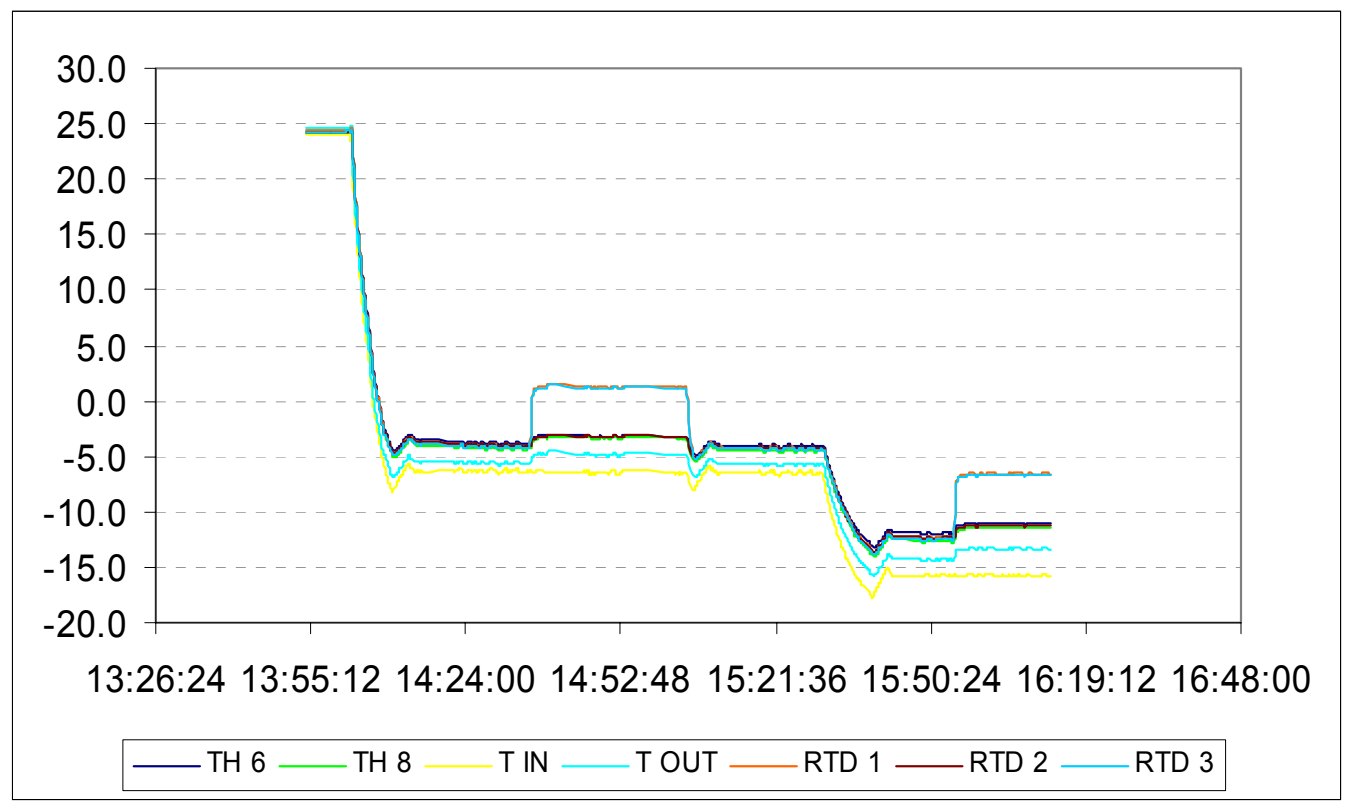

Figure 1-3-Typical data plot already converted in degrees Celsius. Most of the spikes from the chiller trips are filtered.

\section{Heat transfer analysis}

The net heat removed from the stave can be calculated, once the mass flow and the temperature difference between inlet and outlet are known, from the relation

$Q_{\text {out }}=\dot{m} \cdot C_{p} \cdot\left(T_{\text {out }}-T_{\text {in }}\right)-Q^{*}$

Equation 1-1

where the $Q^{*}$ term is the measured heat that enters the system in the piece of cooling tube between the inlet/outlet RTDs and the stave ${ }^{4}$. The mass flow $\dot{m}$ ranged from about $215 \mathrm{~mL} / \mathrm{min}$, with the chiller temperature set at $-19.1^{\circ} \mathrm{C}$, to about $260 \mathrm{~mL} / \mathrm{min}$, with the chiller temperature set at $-9.1^{\circ} \mathrm{C}$.

$C_{p}$ is the specific heat at constant pressure, $T_{i n}$ and $T_{\text {out }}$ are the measured inlet and outlet temperatures respectively.

${ }^{4}$ For a bulk temperature of $-13.8^{\circ} \mathrm{C} Q^{*}$ has been measured equal to $1.25 \mathrm{~W}$ for a $180 \mathrm{~mL} / \mathrm{min}$ flow and $1.7 \mathrm{~W}$ for a $210 \mathrm{~mL} / \mathrm{min}$. For our calculations an average constant value of $1.5 \mathrm{~W}$ has been assumed. 
The heat that enters the cooling line can be express through the coolant film coefficient $h_{c}$ according to the equation

$$
Q_{\text {in_coolant }}=h_{c} \cdot A_{\text {pipe_stave }} \cdot\left(T_{\text {wall }}-T_{\text {bulk }}\right)
$$

Equation 1-2

where $A_{\text {pipe_stave }}$ is the heat exchange area between pipe and stave, $T_{\text {wall }}$ is the temperature at the inner wall of the pipe and $T_{b u l k}$ is the fluid bulk temperature. The film coefficient is given by

$$
h_{c}=N u^{*} \cdot \frac{k_{b u l k}}{D_{H}}
$$

Equation 1-3

with $D_{H}$ hydraulic diameter of the pipe, $k_{b u l k}$ coolant thermal conductivity at the bulk temperature and $\mathrm{Nu}{ }^{*}$ Nusselt number corrected for the difference in coolant viscosity between the bulk and the wall temperature, according to the formula

$$
N u^{*}=N u \cdot\left(\frac{\mu_{\text {bulk }}}{\mu_{\text {wall }}}\right)^{0.14}
$$

with the Nusselt number $N u$ obtained through interpolation of Shah and London data tables for rectangular ducts and uniform heat flux both axially and circumferentially.

The values of $h_{c}$ calculated with the aforementioned approach range between 639.0 and $657.5 \mathrm{~W} / \mathrm{m}^{2} \mathrm{~K}$. The tubing wall temperature, $T_{\text {wall }}$, can be calculated through the relation

$$
T_{\text {wall }}=T_{\text {surf_stave }}-Q_{\text {in_surf_stave }} \cdot R
$$


$T_{\text {sur_stave }}$ is the temperature of the surface (hybrid or sensor region) and $R$ is the thermal resistance between the stave surface and the inner wall of the cooling line. $R$ is likely the quantity with the greatest uncertainty given the difficulty in estimating the real thickness of the glue layers, their real thermal conductivities, and the inevitable air trapped during the gluing operation. $R$ can be calculated with the expression

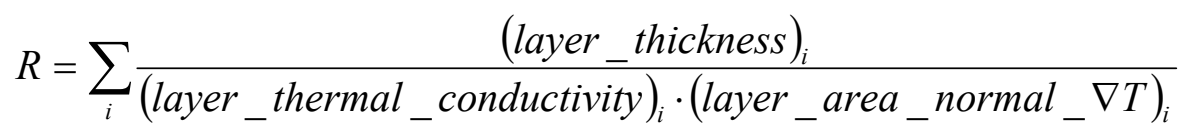

$Q_{\text {in_sur_stave }}$ is the amount of heat entering the surface (hybrid or sensor region), that is the heat dissipated by the heaters plus the heat flowing into the stave from the environment. To minimize this last component the stave has been placed inside a styrene foam box. For energy balance, $Q_{\text {in_surf_stave }}$ must equal the net heat removed from the stave, $Q_{\text {out }}$.

In evaluating $T_{\text {wall }}$ the code (see $\S 6$, Appendix - the code) discriminates the areas under the hybrids from those with only silicon using different values for the thermal resistance $R$, for the temperature of the stave surface, $T_{\text {surf_stave }}$, and for the heat flowing into the coolant from the stave, $Q_{\text {in_surf_stave }}$. 


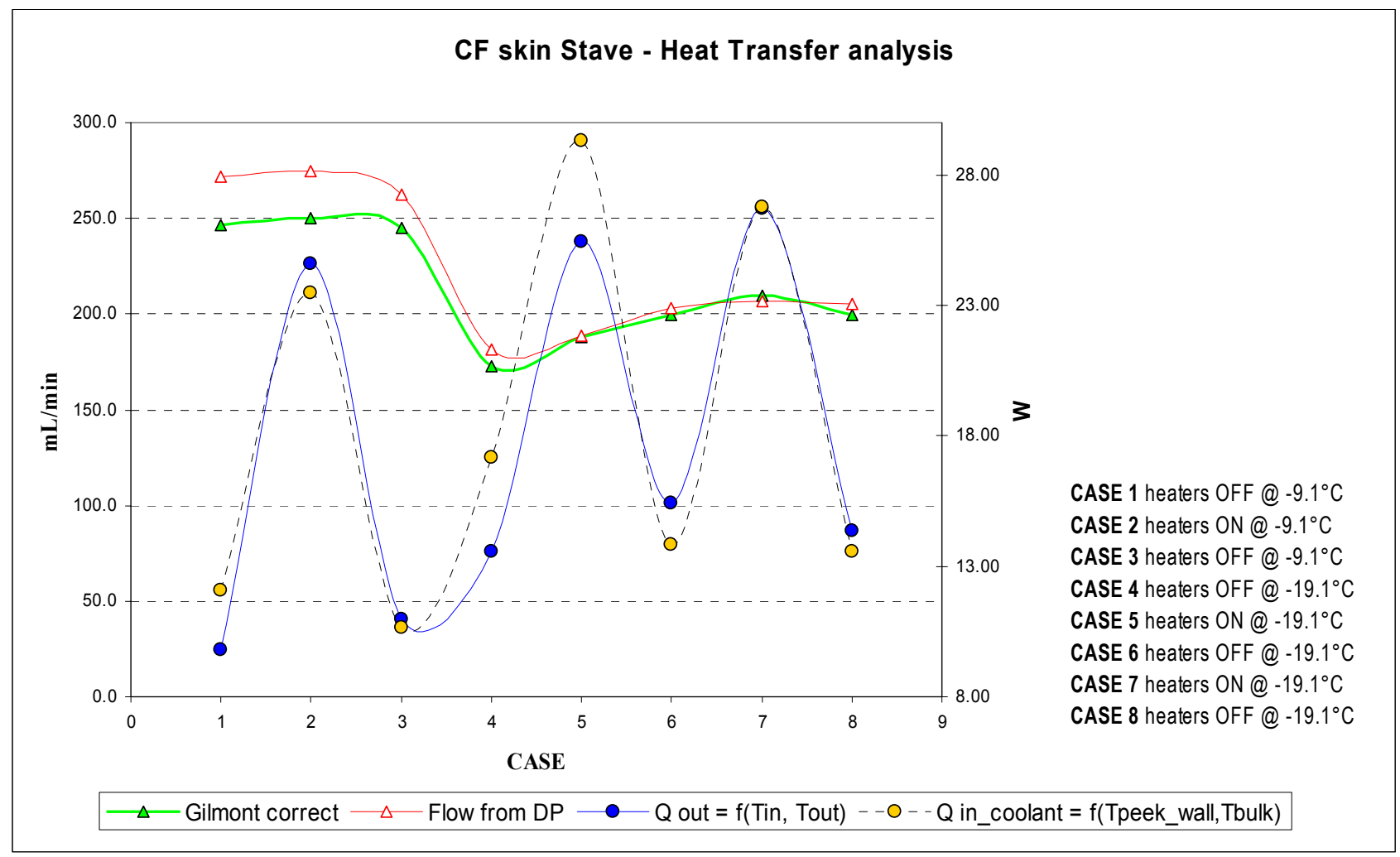

Figure 1-4-Comparison between the total heat leaving the stave ( $Q$ out), given as a function of the temperature difference between outlet and inlet, and the estimated heat entering the fluid ( $Q$ in_coolant) given as a function of the fluid bulk temperature and of the fluid temperature at the wall of the peek tubing. For every test condition (case 1 through 8), the fluid flow has been determined by two independent methods: 1) using the measured flow from the calibrated flowmeter (Gilmont correct) and 2) using the measured $\Delta P$ in the stave to calculate the flow through the tube cross section and the tabulated properties for ethylene glycol $40.6 \%$ volume (see [1]).

An indicator of the validity of the approach is to compare the terms $Q_{\text {out }}$ and $Q_{\text {in_coolant }}$, plotted in Figure 1-4, that for energy balance must be equivalent.

To double check these results, in particular the film coefficient $h_{c}$ of the coolant, a finite element analysis for the stave has been carried out. Three different conditions have been simulated, corresponding to the three cases of the experiment with heaters on, and the following values, corresponding to what has been theoretically calculated (see Figure 1-7), have been assumed 


\begin{tabular}{cccc|}
\multicolumn{1}{c}{} & $\begin{array}{c}T_{\text {bulk }} \\
{\left[{ }^{\circ} \mathrm{C}\right]}\end{array}$ & $\begin{array}{c}h_{\text {c coolant }} \\
{\left[\mathrm{W} / \mathrm{m}^{2} \mathrm{~K}\right]}\end{array}$ & $\begin{array}{c}h_{c} \text { air } \\
{\left[\mathrm{W} / \mathrm{m}^{2} \mathrm{~K}\right]}\end{array}$ \\
\cline { 2 - 4 } case 1 & -5.7 & 657 & 8.1 \\
\hline case 2 & -11.85 & 649 & 8 \\
\hline \multirow{2}{*}{ case 3 } & -14.5 & 646 & 6.7 \\
\cline { 2 - 4 }
\end{tabular}

Table 1-1-FEA case studies

The bulk temperature $T_{b}$ of the coolant is the arithmetic average between the temperatures at the inlet and the outlet of the stave. The film coefficient of the air is calculated as follows

$$
h_{c_{-} \text {air }}=\frac{Q_{\text {out }}-Q_{\text {heaters }}}{A_{\text {stave }} \cdot\left(T_{\text {room }}-\bar{T}_{\text {stave }}\right)}
$$

$Q_{\text {out }}$ is net heat removed from the stave, $Q_{\text {heaters }}$ is the heat dissipated by the strain gages and, $A_{\text {stave }}$ is the total surface areas of the stave, $T_{\text {room }}$ is the room temperature and

$$
\bar{T}_{\text {stave }}=T_{\text {hybrid }} \cdot \frac{4 A_{\text {hybrid }}}{A_{\text {stave }}}+T_{\text {silicon }} \cdot \frac{A_{\text {silicon }}}{A_{\text {stave }}}
$$

Equation 1-8

The Equation 1-8 represents the stave surface temperature, evaluated as the weighted average of the temperatures on the different stave regions.

In Figure 1-5, the temperature profile along the stave - calculated with the FE method - is shown together with the temperatures provided by the sensors in the five control points (see Figure 1-2). The four peaks in the temperature plot represent the location where the heaters are mounted.

For two out of three cases the agreement between FEA prediction and measured data is excellent. The remaining third case study - red colour in the plot of Figure 1-5 - has an error of about 30-37\%; in this case the measured temperature is higher than theoretically predicted. A possible explanation is that the 
stave surface was not at steady state conditions yet; indeed that set of data were acquired at the beginning of the experiment, starting from about $24^{\circ} \mathrm{C}$ room temperature conditions ${ }^{5}$.

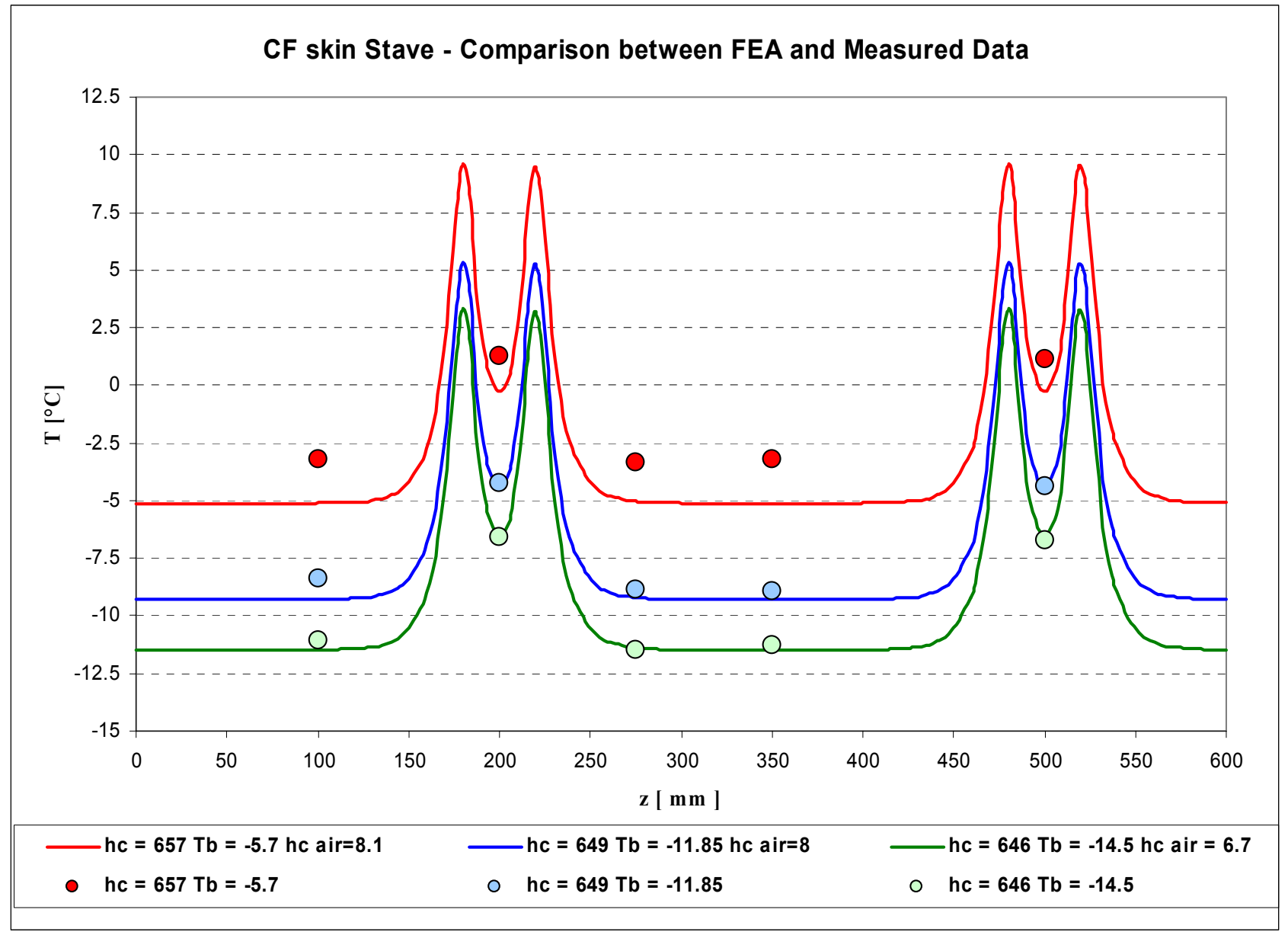

Figure 1-5 - Temperature profile of the stave center line: comparison between measured data and finite element analysis based on theoretical prediction of fluid and air film coefficients. The temperature control points are the same shown in Figure 1-2.

\footnotetext{
${ }^{5}$ Chiller problems made it difficult to operate for long periods
} 


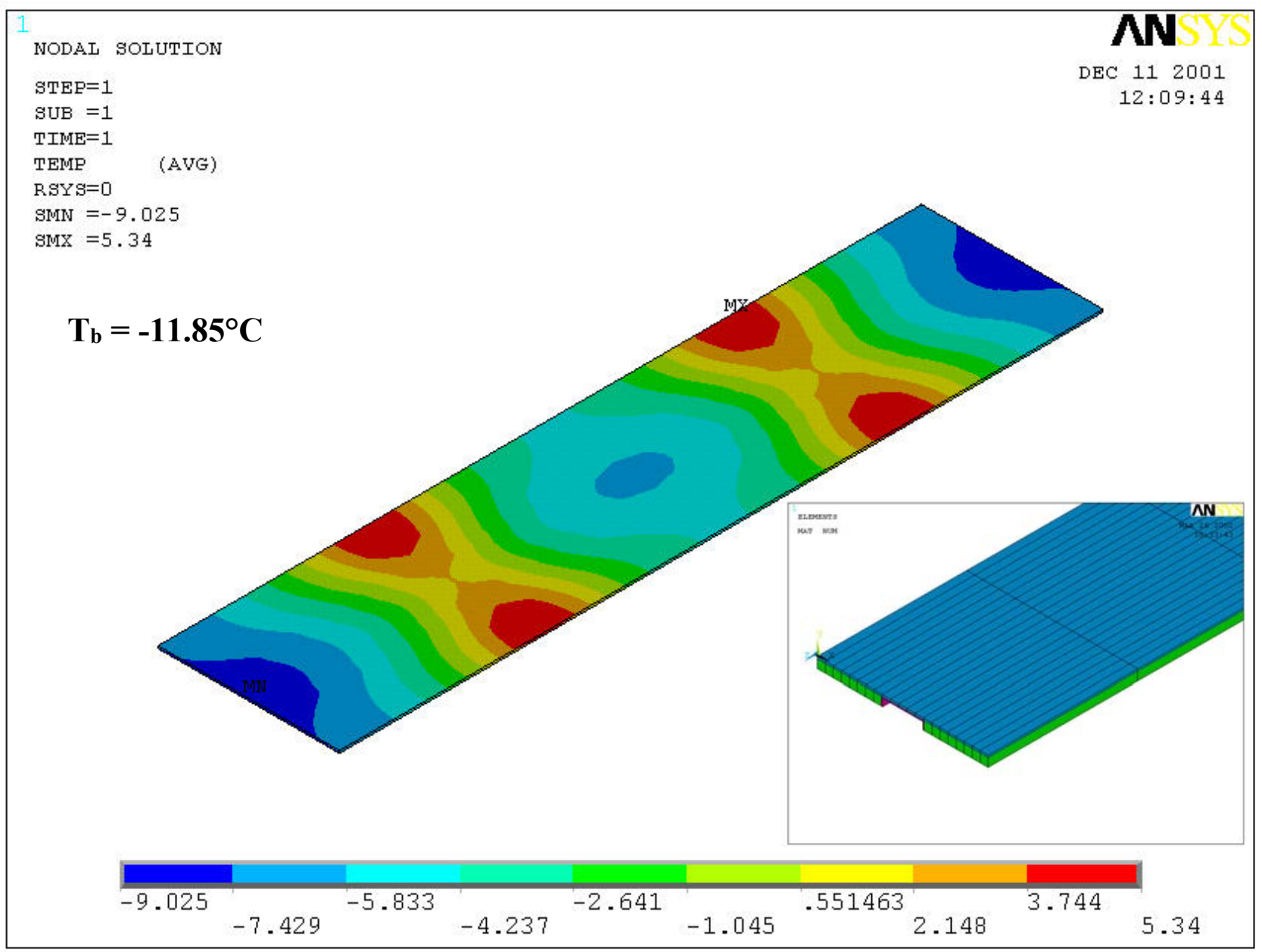

Figure 1-6 - Contour plot of half stave surface (width wise) under the hybrid for $T_{b}=-11.85^{\circ} \mathrm{C}, h_{c}$ coolant $=649 \mathrm{~W} / \mathrm{m}^{2} \mathrm{~K}, h_{c}$ air $=8 \mathrm{~W} / \mathrm{m}^{2} \mathrm{~K}$. The two red-yellow-orange bands indicate where the chips are located. The cooling line passes along the center line of the section shown. In the small figure, in blue the carbon fiber skin, in green the Rohacell core and in magenta the PEEK tubing (5.2mm $\times 1.8 m m$ - inner dimensions).

\section{Conclusions of these experiments}

The tests showed that with a bulk temperature of $-14.5^{\circ} \mathrm{C}$ and a dissipated heat of $1.75 \mathrm{~W}$ per strain gage, the achieved temperature on the stave surface is below $-11^{\circ} \mathrm{C}$, the peak temperature being $+3^{\circ} \mathrm{C}$ under the hybrid chips (FE result). The region adjacent to the chips is characterized by strong temperature gradients $\left(-6.6^{\circ} \mathrm{C}\right.$ at the center of the hybrid region, value confirmed experimentally), area that roughly extends for a span twice the length of the hybrid itself (see Figure 1-6). 
The calculated coolant film coefficient, although slightly dependant on the bulk temperature, is about $650 \mathrm{~W} / \mathrm{m}^{2} \mathrm{~K}$ for a $5.2 \mathrm{~mm}$ by $1.8 \mathrm{~mm}$ pipe. A confirmation of the validity of this result comes from the good agreement of the finite element analysis with the measured data. The temperature drop between the stave surface (carbon fiber skin) and the inner wall of the cooling pipe has been calculated to be $0.6^{\circ} \mathrm{C}$ far from the hybrids, and $2.5^{\circ} \mathrm{C}$ at the center of the hybrid region.

A numeric summary is given in Figure 1-7.

\begin{tabular}{|c|c|c|c|c|c|c|c|c|}
\hline & \multicolumn{7}{|c|}{ AVERAGED MEASURED TEMPERATURES } & \multirow[b]{2}{*}{$\begin{array}{l}\text { MEAS. } \\
\text { DP [psi] }\end{array}$} \\
\hline & T IN & T OUT & RTD 1 & RTD 2 & RTD 3 & TH 6 & TH 8 & \\
\hline heaters OFF @ $-9.1^{\circ} \mathrm{C}$ & -6.3 & -5.6 & -4.0 & -4.0 & -4.2 & -3.8 & -4.3 & 3.70 \\
\hline heaters ON @ $-9.1^{\circ} \mathrm{C}$ & -6.5 & -4.9 & 1.2 & -3.2 & 1.1 & -3.2 & -3.4 & 3.70 \\
\hline heaters OFF @ $-9.1^{\circ} \mathrm{C}$ & -6.5 & -5.7 & -4.2 & -4.3 & -4.4 & -4.1 & -4.5 & 3.60 \\
\hline heaters OFF @ $-19.1^{\circ} \mathrm{C}$ & -15.7 & -14.3 & -12.1 & -12.3 & -12.2 & -11.9 & -12.6 & 3.90 \\
\hline heaters ON @ $-19.1^{\circ} \mathrm{C}$ & -15.7 & -13.3 & -6.6 & -11.3 & -6.7 & -11.1 & -11.5 & 3.95 \\
\hline heaters OFF @ $-19.1^{\circ} \mathrm{C}$ & -13.0 & -11.6 & -9.7 & -9.9 & -10.0 & -9.1 & -9.9 & 3.78 \\
\hline heaters ON @ $-19.1^{\circ} \mathrm{C}$ & -13.0 & -10.7 & -4.2 & -8.9 & -4.4 & -8.4 & -8.9 & 3.75 \\
\hline \multirow[t]{2}{*}{ heaters OFF @-19.1은 } & -12.9 & -11.6 & -9.8 & -9.9 & -10.1 & -9.1 & -9.9 & 3.80 \\
\hline & T bulk & T stave & $\begin{array}{l}\text { density } \\
{[\mathrm{gm} / \mathrm{mL}]}\end{array}$ & $\begin{array}{c}\text { viscosity } \\
{[c p]}\end{array}$ & S.D. & $\begin{array}{l}\text { Gil.Flow } \\
\text { [mL/min] }\end{array}$ & & \\
\hline heaters OFF @ $-9.1^{\circ} \mathrm{C}$ & -5.97 & -4.1 & 1.068 & 7.29 & 66.0 & 261.0 & & \\
\hline heaters ON @ $-9.1^{\circ} \mathrm{C}$ & -5.67 & -0.3 & 1.068 & 7.06 & 66.0 & 265.0 & & \\
\hline heaters OFF @ $-9.1^{\circ} \mathrm{C}$ & -6.13 & -4.3 & 1.068 & 7.32 & 66.0 & 260.0 & & \\
\hline heaters OFF @ $-19.1^{\circ} \mathrm{C}$ & -15.00 & -12.2 & 1.070 & 11.15 & 65.0 & 189.0 & & \\
\hline heaters ON @-19.1 ${ }^{\circ} \mathrm{C}$ & -14.53 & -8.2 & 1.070 & 10.57 & 66.0 & 204.0 & & \\
\hline heaters OFF @ $-19.1^{\circ} \mathrm{C}$ & -12.28 & -9.83 & 1.070 & 9.69 & 65.5 & 215.0 & & \\
\hline heaters ON @ $-19.1^{\circ} \mathrm{C}$ & -11.85 & -5.86 & 1.069 & 9.26 & 66.0 & 225.0 & & \\
\hline \multirow[t]{2}{*}{ heaters OFF @-19.1 ${ }^{\circ} \mathrm{C}$} & -12.25 & -9.9 & 1.070 & 9.69 & 65.5 & 215.0 & & \\
\hline & $\begin{array}{l}\text { Gilmont } \\
\text { correct } \\
\text { [mL/min] }\end{array}$ & $\begin{array}{c}\text { Flow } \\
\text { from DP } \\
{[\mathrm{mL} / \mathrm{min}]}\end{array}$ & $\begin{array}{c}\text { hc air } \\
{\left[\mathrm{W} / \mathrm{m}^{2} \mathrm{~K}\right]}\end{array}$ & $\begin{array}{c}\text { hc } \\
\text { coolant } \\
{\left[\mathrm{W} / \mathrm{m}^{2} \mathrm{~K}\right]}\end{array}$ & $\begin{array}{c}\text { heat } \\
\text { AIR_Si } \\
{[\mathrm{W}]}\end{array}$ & $\begin{array}{c}\text { heat IN } \\
\text { hybrids } \\
\text { [W] }\end{array}$ & $\begin{array}{l}\text { Q fluid = } \\
\text { f(Tin, } \\
\text { Tout) [W] }\end{array}$ & $\begin{array}{c}Q \text { in }= \\
f(T p e e k \\
\text { wall,Tbul } \\
\text { k) [W] }\end{array}$ \\
\hline heaters OFF @ $-9.1^{\circ} \mathrm{C}$ & 246.3 & 271.6 & 6.85 & 651.72 & 6.51 & 3.27 & 9.78 & 12.07 \\
\hline heaters ON @ -9.1ํㅡ & 250.4 & 274.7 & 8.09 & 657.48 & 7.48 & 17.11 & 24.58 & 23.45 \\
\hline heaters OFF @ $-9.1^{\circ} \mathrm{C}$ & 245.2 & 262.4 & 7.60 & 650.75 & 7.31 & 3.65 & 10.96 & 10.64 \\
\hline heaters OFF @ $-19.1^{\circ} \mathrm{C}$ & 172.5 & 181.3 & 7.38 & 638.99 & 9.07 & 4.52 & 13.59 & 17.15 \\
\hline heaters ON @ $-19.1^{\circ} \mathrm{C}$ & 188.0 & 188.8 & 6.69 & 646.44 & 8.01 & 17.44 & 25.45 & 29.31 \\
\hline heaters OFF @ $-19.1^{\circ} \mathrm{C}$ & 199.3 & 203.5 & 8.96 & 641.44 & 10.30 & 5.14 & 15.44 & 13.81 \\
\hline heaters ON @-19.1 ${ }^{\circ} \mathrm{C}$ & 209.5 & 206.6 & 8.00 & 648.99 & 8.93 & 17.81 & 26.73 & 26.74 \\
\hline heaters OFF @-19.1ํ & 199.3 & 205.1 & 8.32 & 641.37 & 9.56 & 4.79 & 14.35 & 13.54 \\
\hline
\end{tabular}

Figure 1-7-Averaged measured temperatures [ $\left.{ }^{\circ} \mathrm{C}\right]$ in different conditions (on-board stave heaters on/off, different T@ chiller), fluid and thermodynamic properties. 


\section{Expectations for the final stave geometry and heat loads}

Since the actual stave design has gone through a continuous refinement, a further finite element study has been performed. The stave width is now $46 \mathrm{~mm}$ and the core lay-up is (see square in Figure 1-9)

1. $2 \mathrm{~mm}$ Rohacell [center core]

2. $350 \mu \mathrm{m}$ glue + kapton + glue [both sides]

3. $320 \mu \mathrm{m}$ silicon sensor [both sides]

4. $950 \mu \mathrm{m}$ hybrid (BeO substrate $380 \mu \mathrm{m}$ thick) [both sides, $50 \mathrm{~mm}$ long]

The pipe inner size is $7.2 \mathrm{~mm} \times 1.8 \mathrm{~mm}$. For a bulk temperature of $-15^{\circ} \mathrm{C}$ and the given pipe geometry the calculated film coefficient is $\sim 700 \mathrm{~W} / \mathrm{m}^{2} \mathrm{~K}$. Only the heat dissipated by the hybrids ( $5 \mathrm{~W} /$ hybrid) has been modeled, the heat generation in the sensors and the heat exchanged by convection with the environment have been neglected.

The double thermal and geometrical symmetry in the stave has allowed to simplify the model, restricting the study to one quarter section only and to a longitudinal region of $150 \mathrm{~mm}$ centered on the hybrid.

Two different silicon temperature profiles have been represented in Figure 1-8:

- the red trace refers to an equivalent conductivity of $100.4 \mathrm{~W} / \mathrm{mK}$, obtained scaling the beryllia substrate thermal conductivity by the substrate to hybrid thickness ratio (380/950). The temperature distribution along the pipe midline inner wall, blue line in Figure 1-8, refers to this case;

- the green dots refer to the ideal case that the hybrid thermal conductivity matches that of the $\mathrm{BeO}$ substrate $(251 \mathrm{~W} / \mathrm{mK})$.

Although the silicon temperature profiles for both cases are similar, a higher hybrid thermal conductivity helps to better spread the heat longitudinally with a beneficial leveling of the temperature gradient.

The maximum silicon temperature is reached under the hybrid and is slightly under $0^{\circ} \mathrm{C}$. Far from the readout chips the silicon temperature falls to about $-10.8^{\circ} \mathrm{C}$. The temperature drop between the silicon surface and the PEEK inner wall is $10.5^{\circ} \mathrm{C}$ under the hybrid and $3^{\circ} \mathrm{C}$ far from it. 


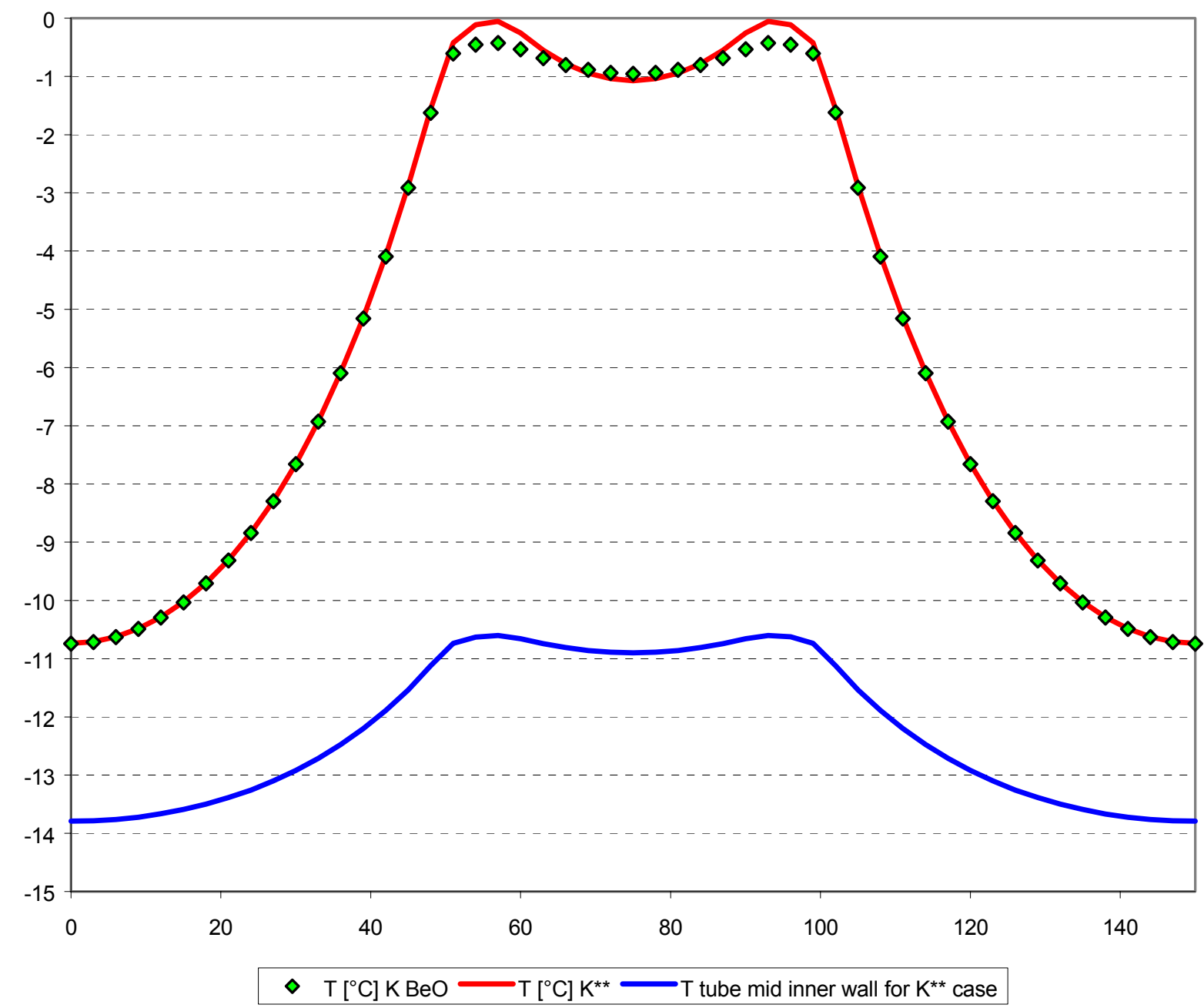

Figure 1-8 - Temperature profile along the cooling pipe inner wall (blue line) and along the silicon sensor center line for hybrid's thermal conductivity equal to $251 \mathrm{~W} / \mathrm{mK}$ (green dots) and equal to $100.4 \mathrm{~W} / \mathrm{mK}$ (red line). Tube inner size: $7.2 \mathrm{~mm}$ $\times 1.8 \mathrm{~mm} ; T_{b}=-15^{\circ} \mathrm{C} ; h_{c}=700 \mathrm{~W} / \mathrm{m}^{2} \mathrm{~K}$. 


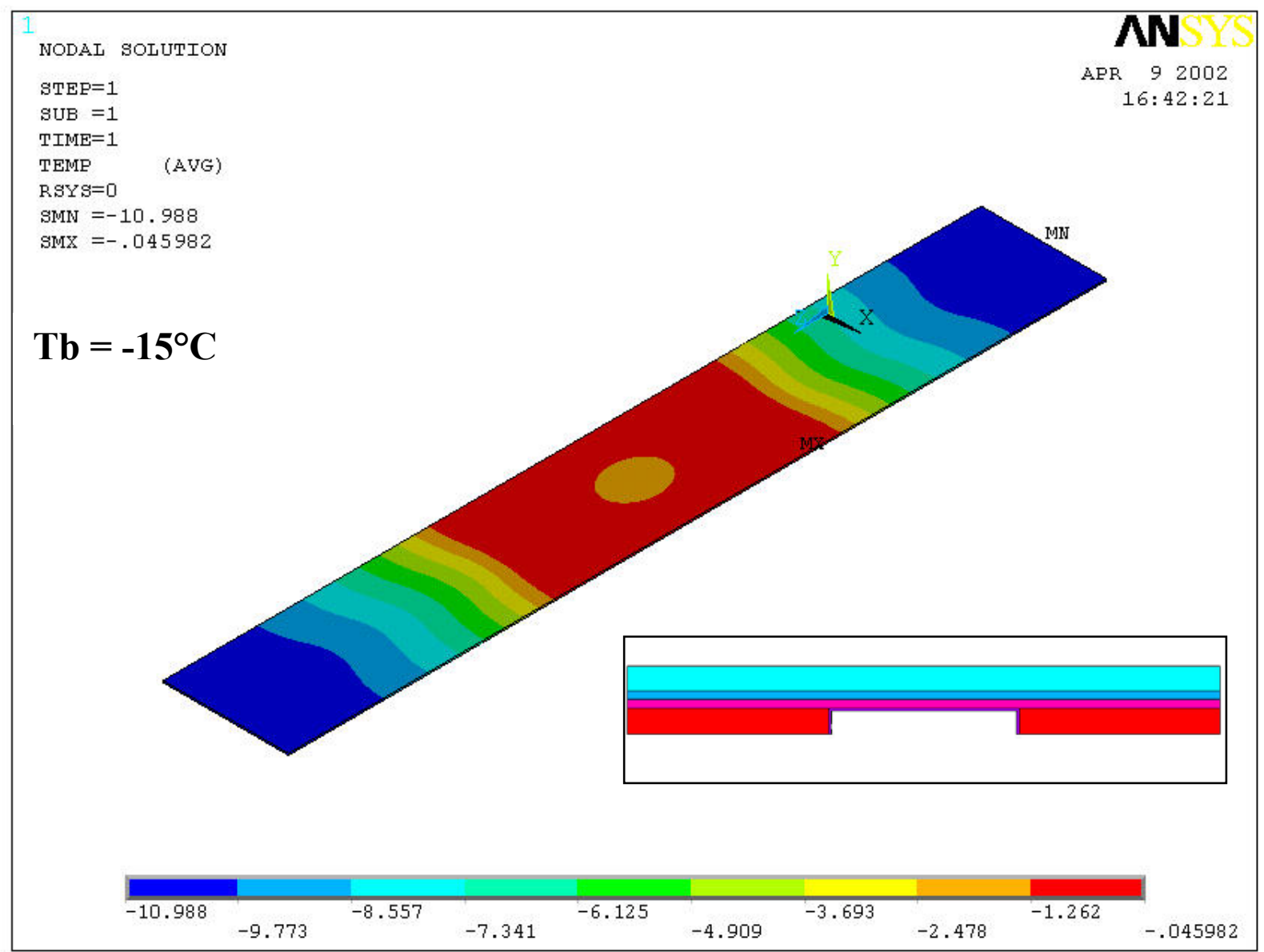

Figure 1-9 - Silicon sensor temperature distribution for $k_{\text {hybrid }}=100.4 \mathrm{~W} / \mathrm{mK}$ over a region of $150 \mathrm{~mm}$ centered on the hybrid. Core lay-up: red, Rohacell; violet, PEEK tubing; magenta, kapton with two glue layers; blue, silicon sensor; light blue, hybrid. Tube inner size: $7.2 \mathrm{~mm} \times 1.8 \mathrm{~mm} ; T_{b}=-15^{\circ} \mathrm{C} ; h_{c}=700 \mathrm{~W} / \mathrm{m}^{2} \mathrm{~K}$. 


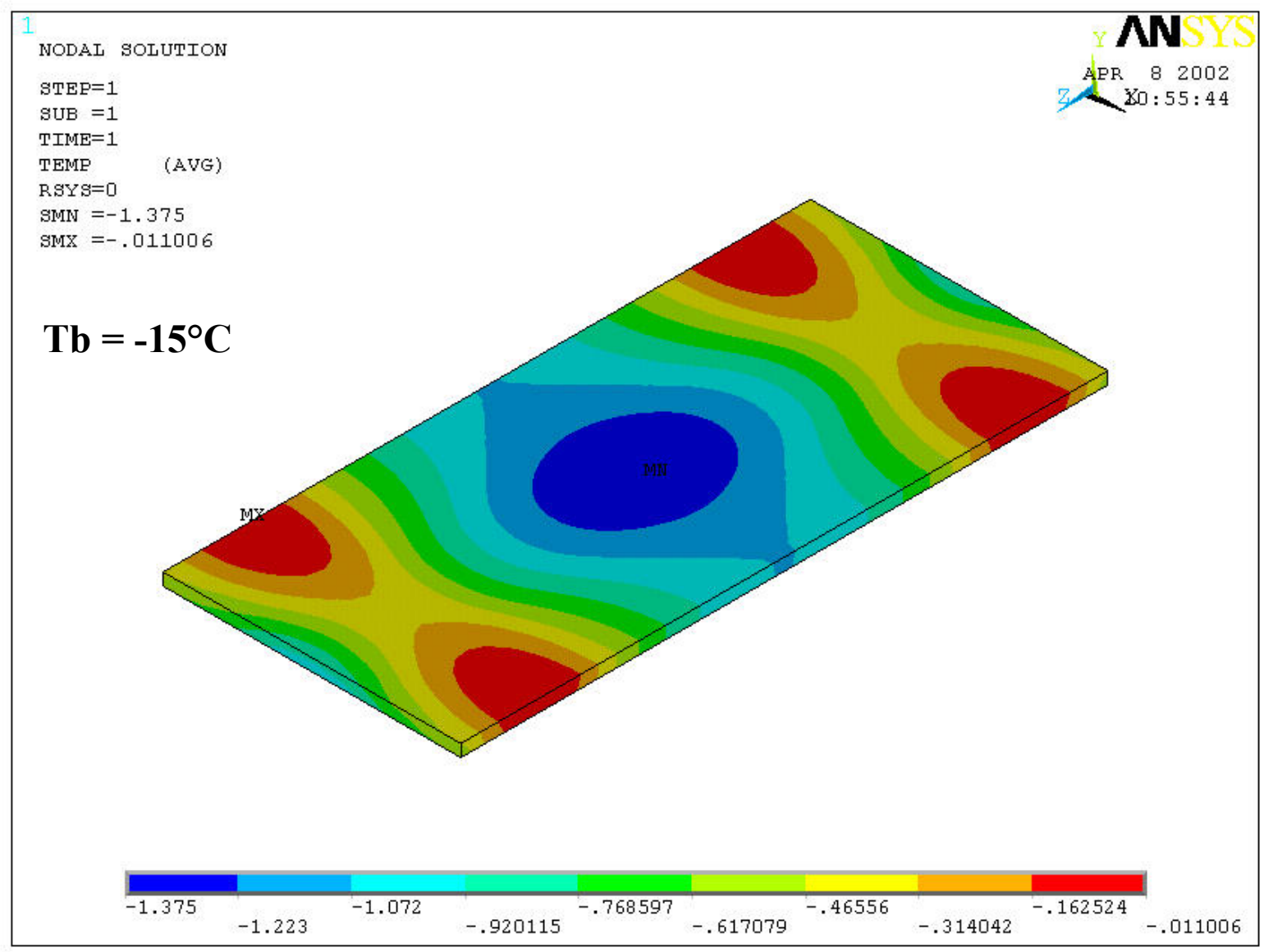

Figure 1-10 - Hybrid temperature distribution. Equivalent conductivity $k_{\text {hybrid }}=100.4 \mathrm{~W} / \mathrm{mK}$. Tube inner size: $7.2 \mathrm{~mm} \times$ $1.8 \mathrm{~mm} ; T_{b}=-15^{\circ} \mathrm{C} ; h_{c}=700 \mathrm{~W} / \mathrm{m}^{2} \mathrm{~K}$.

\section{Appendix - the code}

The data refer to the case with heaters on and $\mathrm{T}$ chiller set at $-19.1^{\circ} \mathrm{C}$.

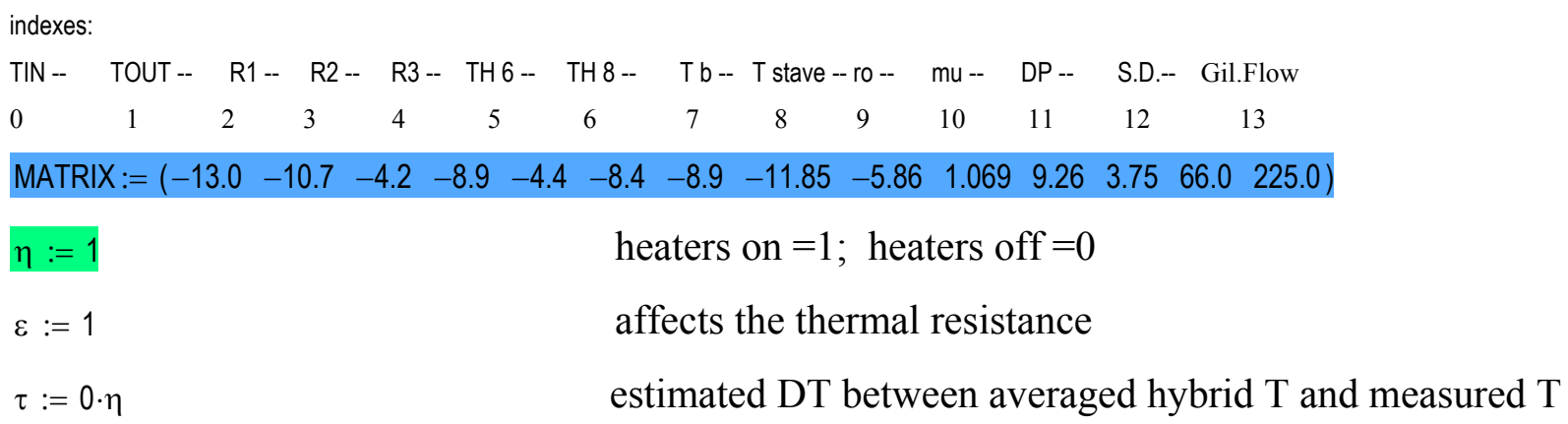




$$
\begin{aligned}
& \mathrm{T}_{\text {room }}:=24.3 \quad \text { Room T } \\
& \Delta P:=\text { MATRIX }_{0,11} p s i \quad \text { Pressure drop in psi } \\
& \text { FLOW := MATRIX }{ }_{0,13} \quad \text { flow rate from Gimont software - to be input dimensionless } \\
& Q_{\text {heaters }}:=2 \cdot 6.98 \mathrm{~W} \cdot \eta \quad \text { power from heaters in all hybrids } \\
& \mathrm{T}_{\mathbb{N}}:=\text { MATRIX }_{0,0} \\
& \text { TOUT : }=\text { MATRIX }_{0,1} \\
& \operatorname{mean}\left[\left(\text { MATRIX }_{0,2}\right),\left(\text { MATRIX }_{0,4}\right)\right]=-4.3 \\
& \mathrm{~T}_{\text {silicon }}:=\operatorname{MATRIX}_{0,3} \\
& \mathrm{~T}_{\text {silicon }}=-8.9 \\
& T_{\text {hybrid }}:=\operatorname{mean}\left[\left(\text { MATRIX }_{0,2}\right),\left(\text { MATRIX }_{0,4}\right)\right]+\tau \\
& T_{\text {hybrid }}=-4.3 \\
& \mathrm{~T}_{\mathrm{b}}:=\frac{\mathrm{T}_{\mathrm{IN}}+\mathrm{T}_{\text {OUT }}}{2} \\
& T_{b}=-11.85 \\
& \text { per_mass }:=42.5 \quad \text { ethylene glycol concentration (mass) }
\end{aligned}
$$

- Geometry

Stave

$$
\begin{aligned}
& \mathrm{W}_{\text {stave }}:=42 \cdot \mathrm{mm} \\
& \mathrm{L}_{\text {stave }}:=600 \mathrm{~mm} \\
& \mathrm{~A}_{\text {stave }}:=\mathrm{L}_{\text {stave }} \cdot \mathrm{W}_{\text {stave }} \\
& \text { perimeter }:=\left(\mathrm{W}_{\text {stave }}+\mathrm{L}_{\text {stave }}\right) \cdot 2
\end{aligned}
$$

1 hybrid (the area is doubled to keep into account the heat spreading longitudinally into the silicon)

Lybrid $:=2.50 \cdot \mathrm{mm}$

$A_{\text {hybrid }}:=W_{\text {stave }} \cdot$ Lhybrid

perimeter $_{\text {hybrid }}:=2 \cdot\left(\mathrm{W}_{\text {stave }}+L_{\text {hybrid }}\right)$ 
silicon (one side)

$\mathrm{L}_{\text {silicon }}:=\mathrm{L}_{\text {stave }}-2 \mathrm{~L}_{\text {hybrid }}$

$A_{\text {silicon }}:=W_{\text {stave }} \cdot L_{\text {silicon }}$

perimeter silicon $:=2 \cdot\left(\mathrm{W}_{\text {stave }}+\mathrm{L}_{\text {silicon }}\right)$

Pipe line

$\mathrm{L}_{\text {rect_pipe }}:=2 \cdot \mathrm{L}_{\text {stave }}+2 \cdot 10 \cdot \mathrm{mm}$

$L_{\text {round_pipe_stave }}:=2 \cdot 30 \mathrm{~mm}+(2 \cdot 50+\pi \cdot 15) \mathrm{mm}$

$L_{\text {round_pipe_out }}:=480 \mathrm{~mm}+370 \mathrm{~mm}$

$L_{\text {round_pipe }}:=L_{\text {round_pipe_stave }}+L_{\text {round_pipe_out }}$

total round pipe between pressure control points

Stadium shape pipe geometry

$\mathrm{h}:=1.8 \mathrm{~mm}$

height

$I:=\frac{\pi \cdot 0.158 \mathrm{in}-\pi \cdot 1.8 \mathrm{~mm}}{2}$

$\mathrm{W}:=\mathrm{I}+\mathrm{h}$

$w=5.276 \mathrm{~mm}$

width

A cross_rect $_{\text {in }}:=I \cdot h+\pi \cdot\left(\frac{h}{2}\right)^{2}$

rect_wetted_perimeter $:=2 \cdot 1+\pi \cdot h$

$\mathrm{D}_{\mathrm{H}}:=4 \frac{\mathrm{A}_{\text {cross_rect }}}{\text { rect_wetted_perimeter }}$

Round pipe geometry

$D_{\mathrm{rp}}:=\frac{3}{16}$ in

$\mathrm{D}_{\mathrm{rp}}=4.762 \mathrm{~mm}$

$A_{\text {cross_round }}:=\pi \cdot\left(\frac{\mathrm{D}_{\mathrm{rp}}}{2}\right)^{2}$

Contact area between pipe and 1 hybrid (for 2 pipes)

$A_{\text {pipe_hybrid }}:=2 \cdot w L_{\text {hybrid }}$

Contact area between pipe and one side silicon (for 2 pipes) 
$A_{\text {pipe_silicon }}:=2 \cdot w \cdot L_{\text {silicon }}$

- $\quad$ Air properties @, the average T $\left(0^{\circ} \mathrm{C}\right)$

$$
\begin{aligned}
& \mathrm{k}_{\text {air }}:=0.0237 \frac{\mathrm{W}}{\mathrm{m} \cdot \mathrm{K}} \\
& \mathrm{Cp}:=1011 \frac{\mathrm{J}}{\mathrm{kg} \cdot \mathrm{K}} \\
& \rho:=1.252 \frac{\mathrm{kg}}{\mathrm{m}^{3}} \\
& \beta:=3.66 \cdot \frac{10^{-3}}{\mathrm{~K}} \\
& \mu:=17.456 \cdot 10^{-6} \mathrm{~N} \cdot \frac{\mathrm{s}}{\mathrm{m}^{2}} \\
& \mu=0.017 \frac{\mathrm{poise}}{100} \\
& \operatorname{Pr}_{\text {air }}:=\frac{\mathrm{Cp} \cdot \mu}{\mathrm{k}}
\end{aligned}
$$

- Ethylene Glycol PROPERTIES - viscosity 20\% vol ETHYLENE GLYCOL

$$
\begin{aligned}
& \text { data }:=\left(\begin{array}{cc}
-5 & 3.65 \\
0 & 3.02 \\
5 & 2.54 \\
10 & 2.18 \\
15 & 1.89 \\
20 & 1.65 \\
25 & 1.46
\end{array}\right) \\
& 301.30) \\
& X:=\text { data }\langle 0\rangle \text { csort(data,0) } \\
& \left.Y:=\text { data }{ }_{1}\right\rangle
\end{aligned}
$$


$S:=$ cspline $(X, Y)$

$\mu 20(T):=\operatorname{interp}(S, X, Y, T) \cdot P a \cdot \frac{S}{1000}$

$30 \%$ vol ETHYLENE GLYCOL

data $:=\left(\begin{array}{cc}-10 & 6.19 \\ -5 & 5.03 \\ 0 & 4.15 \\ 5 & 3.48 \\ 10 & 2.95 \\ 15 & 2.53 \\ 20 & 2.20\end{array}\right)$

data $:=\operatorname{csort}($ data, 0$)$

$X:=$ data $^{\langle 0\rangle}$

$Y:=$ data $^{\langle 1\rangle}$

$S:=$ cspline $(X, Y)$

$\mu 30(T):=\operatorname{interp}(S, X, Y, T) \cdot P a \cdot \frac{S}{1000}$

$40 \%$ vol ETHYLENE GLYCOL

$\operatorname{data}:=\left(\begin{array}{cc}-20 & 15.75 \\ -15 & 11.74 \\ -10 & 9.06 \\ -5 & 7.18 \\ 0 & 5.83 \\ 5 & 4.82 \\ 10 & 4.04 \\ 15 & 3.44 \\ 20 & 2.96\end{array}\right)$

data $:=\operatorname{csort}($ data, 0$)$

$X:=$ data $\langle 0\rangle$

$Y:=$ data $^{\langle 1\rangle}$

$S:=$ cspline $(X, Y)$ 
$\mu 40(T):=\operatorname{interp}(S, X, Y, T) \cdot P a \cdot \frac{S}{1000}$

50\% vol ETHYLENE GLYCOL

data $:=\left(\begin{array}{rr}-30 & 43.98 \\ -25 & 30.50 \\ -20 & 22.07 \\ -15 & 16.53 \\ -10 & 12.74 \\ -5 & 10.05 \\ 0 & 8.09 \\ 5 & 6.63 \\ 10 & 5.50 \\ 15 & 4.63 \\ 20 & 3.94\end{array}\right)$

data $:=\operatorname{csort}($ data, 0$)$

$X:=$ data $^{\langle 0\rangle}$

$Y:=$ data $^{\langle 1\rangle}$

$S:=$ cspline $(X, Y)$

$\mu 50(T):=\operatorname{interp}(S, X, Y, T) \cdot P a \cdot \frac{S}{1000}$

viscosity interpolation

data $:=\left[\begin{array}{c}20 \frac{\mu 20\left(T_{b}\right)}{\left(P a \cdot \frac{s}{1000}\right)} \\ 30 \frac{\mu 30\left(T_{b}\right)}{\left(P a \cdot \frac{s}{1000}\right)} \\ 40 \frac{\mu 40\left(T_{b}\right)}{\left(P a \cdot \frac{s}{1000}\right)} \\ 50 \frac{\mu 50\left(T_{b}\right)}{\left(P a \cdot \frac{S}{1000}\right)}\end{array}\right]$ 


$$
\begin{aligned}
& \text { data }:=\operatorname{csort}(\text { data }, 0) \\
& X:=\text { data }\langle 0\rangle \\
& Y:=\text { data }\left\langle{ }_{1}\right\rangle \\
& S:=\operatorname{cspline}(X, Y) \\
& \mu_{\text {bulk }}(\mathrm{X}):=\text { interp }(S, X, Y, x) \cdot P a \cdot \frac{\mathrm{s}}{1000} \\
& \mu_{\mathrm{b}}:=\mu_{\text {bulk }}(\text { per_mass }) \\
& \mu_{\mathrm{b}}=10.89 \frac{\text { poise }}{100}
\end{aligned}
$$

- Ethylene Glycol PROPERTIES - thermal conductivity $20 \%$ vol ETHYLENE GLYCOL

data $:=\left(\begin{array}{cc}-5 & 0.46 \\ 0 & 0.468 \\ 5 & 0.476 \\ 10 & 0.483 \\ 15 & 0.49 \\ 20 & 0.497 \\ 25 & 0.503 \\ 30 & 0.509\end{array}\right)$

data $:=\operatorname{csort}($ data, 0$)$

$X:=$ data $^{\langle 0\rangle}$

$Y:=$ data $^{\langle 1\rangle}$

$S:=$ cspline $(X, Y)$

$k 20(T):=\operatorname{interp}(S, X, Y, T) \cdot \frac{W}{m \cdot K}$

$30 \%$ vol ETHYLENE GLYCOL 
data $:=\left(\begin{array}{cc}-10 & 0.415 \\ -5 & 0.422 \\ 0 & 0.429 \\ 5 & 0.436 \\ 10 & 0.442 \\ 15 & 0.448 \\ 20 & 0.453 \\ 25 & 0.459 \\ 30 & 0.464\end{array}\right)$

data $:=\operatorname{csort}($ data, 0$)$

$X:=$ data $^{\langle 0\rangle}$

$Y:=$ data $^{\left\langle{ }_{1}\right\rangle}$

$S:=$ cspline $(X, Y)$

$\mathrm{k} 30(\mathrm{~T}):=\operatorname{interp}(\mathrm{S}, \mathrm{X}, \mathrm{Y}, \mathrm{T}) \cdot \frac{\mathrm{W}}{\mathrm{m} \cdot \mathrm{K}}$

40\% vol ETHYLENE GLYCOL

data $:=\left(\begin{array}{cc}-20 & 0.371 \\ -15 & 0.377 \\ -10 & 0.383 \\ -5 & 0.389 \\ 0 & 0.395 \\ 5 & 0.400 \\ 10 & 0.405 \\ 15 & 0.410 \\ 20 & 0.415 \\ 25 & 0.419 \\ 30 & 0.424\end{array}\right)$

data $:=\operatorname{csort}($ data, 0$)$

$X:=$ data $^{\langle 0\rangle}$

$Y:=$ data $^{\langle 1\rangle}$

$S:=$ cspline $(X, Y)$ 
$\mathrm{k} 40(\mathrm{~T}):=\operatorname{interp}(\mathrm{S}, \mathrm{X}, \mathrm{Y}, \mathrm{T}) \cdot \frac{\mathrm{W}}{\mathrm{m} \cdot \mathrm{K}}$

50\% vol ETHYLENE GLYCOL

data $:=\left(\begin{array}{cc}-20 & 0.344 \\ -15 & 0.349 \\ -10 & 0.354 \\ -5 & 0.359 \\ 0 & 0.364 \\ 5 & 0.368 \\ 10 & 0.373 \\ 15 & 0.377\end{array}\right)$

data $:=\operatorname{csort}($ data, 0$)$

$X:=$ data $^{\langle 0\rangle}$

$\mathrm{Y}:=\operatorname{data}^{\left\langle{ }_{1}\right\rangle}$

$S:=$ cspline $(X, Y)$

$k 50(T):=\operatorname{interp}(S, X, Y, T) \cdot \frac{W}{m \cdot K}$

thermal conductivity interpolation

data $:=\left[\begin{array}{rr}20 & \frac{k 20\left(T_{b}\right)}{\left(\frac{W}{m \cdot K}\right)} \\ 30 & \frac{k 30\left(T_{b}\right)}{\left(\frac{W}{m \cdot K}\right)} \\ 40 & \frac{k 40\left(T_{b}\right)}{\left(\frac{W}{m \cdot K}\right)} \\ 50 & \frac{k 50\left(T_{b}\right)}{\left(\frac{W}{m \cdot K}\right)}\end{array}\right]$

data $:=\operatorname{csort}($ data, 0$)$

$X:=$ data $^{\langle 0\rangle}$ 


$$
\begin{aligned}
& \mathrm{Y}:=\text { data } \\
& \mathrm{S}:=\operatorname{cspline}(\mathrm{X}, \mathrm{Y}) \\
& \mathrm{k}_{\text {bulk }}(\mathrm{X}):=\text { interp }(\mathrm{S}, \mathrm{X}, \mathrm{Y}, \mathrm{X}) \cdot \frac{\mathrm{W}}{\mathrm{m} \cdot \mathrm{K}} \\
& \mathrm{k}_{\mathrm{b}}:=\mathrm{k}_{\text {bulk }} \text { (per_mass) }
\end{aligned}
$$

- Other fluid properties

$$
\begin{aligned}
& C_{p}:=3.334 \cdot \frac{\mathrm{J}}{\mathrm{K} \cdot \mathrm{gm}} \\
& \rho_{\mathrm{b}}:=\text { MATRIX }_{0,9} \frac{\mathrm{gm}}{\mathrm{cm}^{3}} \\
& \operatorname{Pr}:=C_{\mathrm{p}} \cdot \frac{\mu_{\mathrm{b}}}{\mathrm{k}_{\mathrm{b}}} \\
& \operatorname{Pr}=97.191
\end{aligned}
$$

- $\quad$ Flow rate estimate

$\phi$ correction factor for laminar friction coefficient in presence of rectangular cross section

$$
f i:=\left(\begin{array}{cc}
0 & 1.5 \\
0.1 & 1.34 \\
0.3 & 1.10 \\
0.5 & 0.97 \\
0.8 & 0.9 \\
1 & 0.88
\end{array}\right)
$$

fi := $\operatorname{csort}(f i, 0)$

$X:=\mathrm{fi}^{\langle 0\rangle}$

$Y:=f i{ }^{\langle 1\rangle}$

$S:=$ cspline $(X, Y)$

$\phi(\mathrm{x}):=\operatorname{interp}(\mathrm{S}, \mathrm{X}, \mathrm{Y}, \mathrm{X})$

$\phi:=\phi\left(\frac{\mathrm{h}}{\mathrm{w}}\right)$ 
$\phi=1.065$

flow_rate $:=\frac{\Delta P}{\left[\phi \cdot 32 \cdot \mu_{\mathrm{b}} \cdot \frac{\mathrm{L}_{\text {rect_pipe }}}{\left(\mathrm{D}_{\mathrm{H}}\right)^{2}} \cdot\left(\frac{1}{\left.\mathrm{~A}_{\text {cross_rect }}\right)}+32 \cdot \mu_{\mathrm{b}} \frac{\mathrm{L}_{\text {round_pipe }}}{\mathrm{D}_{\mathrm{rp}}{ }^{2}} \cdot\left(\frac{1}{\mathrm{~A}_{\text {cross_round }}}\right)\right]\right.}$

it holds if $\operatorname{Re} \leq 2320$

flow_rate $=206.645 \frac{\text { liter }}{1000 \cdot \min }$

$V_{\text {fluid_rect }}:=\frac{\text { flow_rate }}{A_{\text {cross_rect }}}$

$\operatorname{Re}_{\text {rect }}:=\rho_{\mathrm{b}} \cdot \mathrm{V}_{\text {fluid_rect }} \cdot \frac{\mathrm{D}_{\mathrm{H}}}{\mu_{\mathrm{b}}}$

$\operatorname{Re}_{\text {rect }}=107.262$

$V_{\text {fluid_round }}:=\frac{\text { flow_rate }}{A_{\text {cross_round }}}$

$\operatorname{Re}_{\text {round }}:=\rho_{\mathrm{b}} \cdot \mathrm{V}_{\text {fluid_round }} \cdot \frac{\mathrm{D}_{\mathrm{rp}}}{\mu_{\mathrm{b}}}$

$\mathrm{Re}_{\text {round }}=90.386$

- flow rate - through sperimental data interpolation

The flow rate is calculated in two different ways: a) starting from the values of viscosity, density and flowmeter scale division through the Gilmont software to get a first approximation flow rate value which is corrected through a calibration function that relates the Gilmont values to the data measured experimentally - beaker and chronometer; b) through the measured $\Delta \mathrm{P}$ in the flow.

Gilmont

measured 


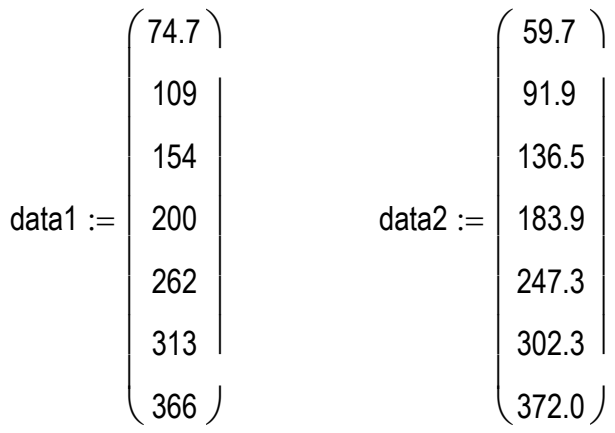

data $:=$ augment(data1, data2)

data $=\left(\begin{array}{cc}74.7 & 59.7 \\ 109 & 91.9 \\ 154 & 136.5 \\ 200 & 183.9 \\ 262 & 247.3 \\ 313 & 302.3 \\ 366 & 372\end{array}\right)$

data $:=\operatorname{csort}($ data, 0$)$

$X:=$ data $\langle 0\rangle$

$Y:=$ data $^{\langle 1\rangle}$

$S:=$ cspline $(X, Y)$

$f \mid w(f):=\operatorname{interp}(S, X, Y, f) \cdot \frac{\mathrm{mL}}{\min }$

gilmont_corrected_flow := flw(FLOW)

gilmont_corrected_flow $=209.5 \frac{\mathrm{mL}}{\mathrm{min}} \quad$ Gilmont corrected flow rate

to be compared from the flow rate calculated with the $\Delta \mathrm{P}$ approach:

flow_rate $=206.645 \frac{\mathrm{mL}}{\mathrm{min}}$

- FILM COEFFICIENT between stave surface and bag

Heat removed from the stave (a contribution of $\sim 1.5 \mathrm{~W}$ is subtracted to keep into account the heat entering in the piece of tube between the TIN-TOUT thermistors and the stave itself): 
$Q_{\text {OUT }}:=\rho_{b} \cdot$ flow_rate $\cdot C_{p} \cdot\left(T_{O U T}-T_{I N}\right) \cdot K$

$\mathrm{Q}_{\mathrm{OUT}}=28.232 \mathrm{~W}$

$Q_{\text {OUT_net }}:=Q_{\text {OUT }}-1.5 \mathrm{~W}$

\section{Q OUT_net $=26.732 \mathrm{~W}$}

$T_{\text {stave }}:=\left(T_{\text {hybrid }} \cdot \frac{2 A_{\text {hybrid }}}{A_{\text {stave }}}+T_{\text {silicon }} \cdot \frac{A_{\text {silicon }}}{A_{\text {stave }}}\right)$

$\mathrm{T}_{\text {stave }}=-7.367$

$h_{\text {C_AIR }}:=\frac{Q_{\text {OUT_net }}-Q_{\text {heaters }}}{2 A_{\text {stave }} \cdot\left(T_{\text {room }}-T_{\text {stave }}\right) \cdot K}$

$\mathrm{h}_{\mathrm{C} \_ \text {AIR }}=8.003 \frac{1}{\mathrm{~m}^{2} \mathrm{~K}} \mathrm{~W}$

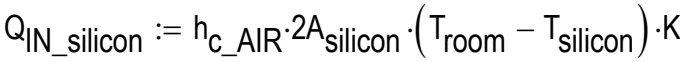

$\mathrm{Q}_{\mathrm{IN} \_ \text {silicon }}=8.927 \mathrm{~W}$

$Q_{I N \_h y b r i d}:=h_{C \_A I R} \cdot 4 A_{\text {hybrid }} \cdot\left(T_{\text {room }}-T_{\text {hybrid }}\right) \cdot K+Q_{\text {heaters }}$

$\mathrm{Q}_{\mathrm{IN} \_ \text {hybrid }}=17.805 \mathrm{~W}$

- $\quad$ FILM COEFFICIENT inside cooling line

${ }^{\mathrm{t}} \mathrm{CF}:=0.2 \mathrm{~mm}$

tPEEK $:=0.1 \mathrm{~mm}$

$\mathrm{t}_{\text {glue }}:=0.05 \mathrm{~mm}$

$k_{2216}:=0.395 \frac{\mathrm{W}}{\mathrm{m} \cdot \mathrm{K}}$

$\mathrm{k}_{\text {PEEK }}:=0.252 \frac{\mathrm{W}}{\mathrm{m} \cdot \mathrm{K}}$

$\mathrm{k}_{\mathrm{CF}}:=0.78 \cdot \frac{\mathrm{W}}{\mathrm{m} \cdot \mathrm{K}}$ heat removed from the stave

heat entering into the Silicon from the environment

heat entering into the hybrids from the heaters + environment 


$$
\begin{aligned}
& R_{\text {PEEK_hybrid }}:=\left(\frac{{ }_{C F}}{k_{C F} \cdot A_{\text {hybrid }}}+t_{\text {glue }} \cdot \frac{1}{k_{2216} \cdot A_{\text {pipe_hybrid }}}+\frac{t_{\text {PEEKK }}}{k_{\text {PEEKK }} \cdot A_{\text {pipe_hybrid }}}\right)^{\varepsilon} \\
& T_{\text {PEEK_hybrid }}:=T_{\text {hybrid }}-\frac{Q_{\text {IN_hybrid }}}{4 \cdot K} \cdot \text { ReEK_hybrid }_{\text {P }} \\
& \text { RPEEK_hybrid }=0.557 \frac{\mathrm{K}}{\mathrm{W}} \\
& \text { TPEEK_hybrid }=-6.8 \\
& R_{\text {PEEK_silicon }}:=\left(\frac{{ }_{C F}}{k_{C F} \cdot A_{\text {silicon }}}+\mathrm{t}_{\text {glue }} \cdot \frac{1}{k_{2216} \cdot A_{\text {pipe_silicon }}}+\frac{{ }_{\text {PEEKK }}}{k_{\text {PEEK }} \cdot A_{\text {pipe_silicon }}}\right)^{\cdot} \cdot \\
& T_{\text {PEEK_silicon }}:=T_{\text {silicon }}-\frac{Q_{\text {IN_silicon }}}{2 \cdot K} \cdot \text { RPEEK_silicon } \\
& \text { RPEEK_silicon }=0.139 \frac{\mathrm{K}}{\mathrm{W}} \\
& \text { TPEEK_silicon }=-9.5
\end{aligned}
$$

- Nusselt number for rectangular ducts

$$
\begin{aligned}
& \text { data }:=\left(\begin{array}{cc}
1 & 3.608 \\
0.5 & 4.123 \\
0.25 & 5.331 \\
0.125 & 6.490
\end{array}\right) \\
& \text { data }:=\operatorname{csort}(\text { data }, 0) \\
& X:=\text { data }\langle 0\rangle \\
& Y:=\operatorname{data}^{\langle 1\rangle} \\
& \mathrm{S}:=\text { cspline }(\mathrm{X}, \mathrm{Y}) \\
& N u_{\text {INTERP }}(X):=\operatorname{interp}(S, X, Y, X) \\
& \mathrm{Nu}:=\operatorname{Nu} \text { INTERP }\left(\frac{h}{w}\right) \\
& \mathrm{Nu}=4.743
\end{aligned}
$$

average Nusselt for uniform heat flux both axially and circumferentially (SHAH \& LONDON) for the given rectangular tube geometry $(\mathrm{h} / \mathrm{w})$ 
data $:=\left[\begin{array}{c}20 \frac{\mu 20(\text { TPEEK_hybrid })}{\left(\text { Pa. } \frac{\mathrm{s}}{1000}\right)} \\ 30 \frac{\mu 30(\text { TPEEK_hybrid })}{\left(\text { Pa. } \frac{\mathrm{s}}{1000}\right)} \\ 40 \frac{\mu 40(\text { TPEEK_hybrid })}{\left(\text { Pa. } \frac{\mathrm{s}}{1000}\right)} \\ 50 \frac{\mu 50(\text { TPEEK_hybrid })}{\left(\mathrm{Pa} \cdot \frac{\mathrm{s}}{1000}\right)}\end{array}\right]$

data $:=\operatorname{csort}($ data, 0$)$

$X:=$ data $^{\langle 0\rangle}$

$Y:=$ data $^{\langle 1\rangle}$

$S:=$ cspline $(X, Y)$

$\mu_{\text {surf_hybrid }}(\mathrm{x}):=\operatorname{interp}(\mathrm{S}, \mathrm{X}, \mathrm{Y}, \mathrm{X}) \cdot \mathrm{Pa} \cdot \frac{\mathrm{S}}{1000}$

$\mu_{\text {PEEK_hybrid }}:=\mu_{\text {surf_hybrid }}$ (per_mass)

Nuss ${ }_{\text {Cooling_hybrid }}:=\mathrm{Nu} \cdot\left(\frac{\mu_{\mathrm{b}}}{\mu_{\text {PEEK_hybrid }}}\right)^{0.14}$

Nuss ${ }_{\text {cooling_hybrid }}=4.911$

correction due to $\mathrm{T}$ differences between bulk and wall temperature 
data $:=\left[\begin{array}{c}20 \frac{\mu 20(\text { TPEEK_silicon })}{\left(\text { Pa. } \frac{\mathrm{s}}{1000}\right)} \\ 30 \frac{\mu 30(\text { TPEEK_silicon })}{\left(\mathrm{Pa} \cdot \frac{\mathrm{s}}{1000}\right)} \\ 40 \frac{\mu 40(\text { TPEEK_silicon })}{\left(\mathrm{Pa} \cdot \frac{\mathrm{s}}{1000}\right)} \\ 50 \frac{\mu 50(\text { TPEEK_silicon })}{\left(\mathrm{Pa} \cdot \frac{\mathrm{s}}{1000}\right)}\end{array}\right]$

data $:=\operatorname{csort}($ data, 0$)$

$X:=$ data $^{\langle 0\rangle}$

$Y:=$ data $^{\langle 1\rangle}$

$S:=$ cspline $(X, Y)$

$\mu_{\text {surf_silicon }}(\mathrm{x}):=\operatorname{interp}(\mathrm{S}, \mathrm{X}, \mathrm{Y}, \mathrm{X}) \cdot \mathrm{Pa} \cdot \frac{\mathrm{S}}{1000}$

$\mu$ PEEK_silicon $:=\mu_{\text {surf_silicon }}($ per_mass)

Nuss_cooling_silicon $:=\mathrm{Nu} \cdot\left(\frac{\mu_{\mathrm{b}}}{\mu_{\text {PEEK_silicon }}}\right)^{0.14}$

Nuss_cooling_silicon $=4.822$

temperature

$h_{C \_ \text {cooling_hybrid }}:=$ Nuss $_{\text {cooling_hybrid }} \cdot \frac{k_{b}}{D_{H}}$

$\mathrm{h}_{\text {C_cooling_hybrid }}=656.967 \frac{1}{\mathrm{~m}^{2} \mathrm{~K}} \mathrm{~W}$

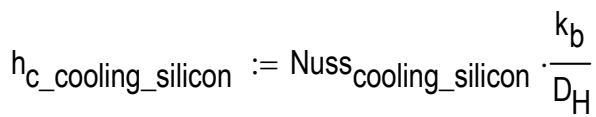

correction due to $\mathrm{T}$ differences between bulk and wall 
$\mathrm{h}_{\mathrm{C} \_ \text {cooling_silicon }}=645.005 \frac{1}{\mathrm{~m}^{2} \mathrm{~K}} \mathrm{~W}$

$h_{\text {C_cooling }}:=\left(h_{\text {C_cooling_hybrid }} \cdot \frac{2 A_{\text {hybrid }}}{A_{\text {stave }}}+h_{\text {c_cooling_silicon }} \cdot \frac{A_{\text {silicon }}}{A_{\text {stave }}}\right)$

$\mathrm{h}_{\mathrm{C} \_ \text {cooling }}=648.992 \frac{1}{\mathrm{~m}^{2} \mathrm{~K}} \mathrm{~W}$

coolant film coefficient

$\mathrm{q}_{\text {IN_cooling_hybrid }}:=\mathrm{h}_{\mathrm{C} \_ \text {cooling_hybrid }} \cdot\left(\mathrm{A}_{\text {pipe_hybrid }} \cdot 4\right) \cdot\left(\mathrm{T}_{\mathrm{PEEK} \_ \text {hybrid }}-\mathrm{T}_{\mathrm{b}}\right) \cdot \mathrm{K}$

qIN_cooling_hybrid $=14.061 \mathrm{~W}$

$\mathrm{q}_{\mathbb{I} \text { _ccooling_silicon }}:=\mathrm{h}_{\text {C_cooling_silicon }} \cdot\left(\mathrm{A}_{\text {pipe_silicon }} \cdot 2\right) \cdot\left(\mathrm{T}_{\mathrm{PEEK} \text { _silicon }}-\mathrm{T}_{\mathrm{b}}\right) \cdot \mathrm{K}$

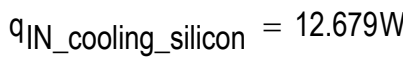

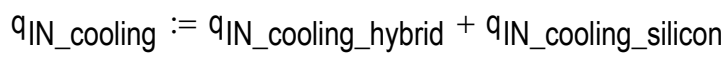

$\mathrm{q}_{\mathrm{IN} \_ \text {cooling }}=26.741 \mathrm{~W}$

heat entering the coolant

QUUT_net $=26.732 \mathrm{~W}$

QOUT_net $-\mathrm{q}_{\mathrm{IN} \_ \text {cooling }}=-0.008 \mathrm{~W}$

it gives an indication of the errors in the estimate of thermal resistance, film coefficients

\section{RESULTS}

RESULT $:=\left[\frac{\text { gilmont_corrected_flow }}{\frac{\mathrm{mL}}{\mathrm{min}}} \frac{\text { flow_rate }}{\frac{\mathrm{mL}}{\min }} \frac{\mathrm{h}_{\mathrm{C} \_A I R}}{\left(\frac{\mathrm{W}}{\mathrm{m}^{2} \mathrm{~K}}\right)} \frac{\mathrm{h}_{\text {C_cooling }}}{\frac{\mathrm{W}}{\mathrm{m}^{2} \mathrm{~K}}} \frac{Q_{\text {IN_silicon }}}{W} \frac{Q_{\text {IN_hybrid }}}{W} \frac{Q_{\text {OUT_net }}}{W} \frac{\mathrm{q}_{\text {IN_cooling }}}{W}\right]$

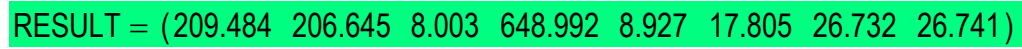

\section{References}

1. « Pressure drop in D0 Run2b stave », G. Lanfranco, Fermilab internal paper

2. «Principles of Heat Transfer», F. Kreith, M.S. Bohn, $6^{\text {th }}$ ed., Brooks/Cole 